\title{
Urbanização, Planejamento e Arborização: uma análise da cidade de Santa Cruz Do Sul/RS
}

Juliana Vanesi Lopes da Silva ${ }^{1}$ Rogério Leandro Lima da Silveira ${ }^{2}$

\begin{abstract}
Resumo
Uma das características mais marcantes das cidades contemporâneas é a presença de grandes centros urbanos cercados por concreto em todos os lados. Para amenizar esse aspecto, a arborização mostra-se como importante estratégia que, além de contribuir para a ornamentação paisagística, proporciona bem-estar a população, melhorando a qualidade do ar, influenciando no microclima entre outros aspectos. No entanto a falta de um planejamento adequado gera diversos problemas impactando negativamente a vida de seus habitantes e danificando os exemplares arbóreos. Considerando essas questões o presente trabalho objetivou analisar o processo de urbanização de Santa Cruz do Sul e sua relação com a política de arborização urbana implementada na cidade, mais especificamente na via principal, a rua Marechal Floriano, a fim de identificar os benefícios da arborização e os principais problemas encontrados a partir da visão dos diversos atores sociais que ali vivem residem e/ou trabalham.
\end{abstract}

Palavras-chave: Arborização urbana. Espaço urbano. Planejamento. Santa Cruz do Sul

\begin{abstract}
One of the most striking features of contemporary cities is the presence of large urban centers surrounded by concrete on all sides. To mitigate this aspect, the afforestation is an important strategy that, in addition to contributing to the landscape ornamentation, provides welfare to the population, improving air quality, influencing the microclimate among other aspects. Nevertheless the lack of a suitable planning generates diverse problems negatively impacting the life of its inhabitants and damaging the arboreal specimens. Considering these issues, the present work aimed to analyze the urbanization process of Santa Cruz do Sul and its relation with the urban afforestation policy implemented in the city, specifically on the main road, Marechal Floriano Street, in order to identify the benefits of afforestation and the main problems found from the perspective of the various social actors who live there reside and/or work.
\end{abstract}

Keywords: Urban planting. Urban space. Planning. Santa Cruz do Sul

\section{Introdução}

O aprofundamento de pesquisas relativas à arborização urbana assume cada vez mais importância no cenário atual, tendo em vista a fundamental contribuição desta para a melhoria da qualidade ambiental e social. A arborização em vias públicas favorece a estabilização do clima, fornece abrigo e alimento à fauna, proporciona sombra, bem como contribui na ornamentação de ruas e avenidas, criando assim espaços de lazer e bem-estar para a população (McHALE; McPHERSON; BURKE, 2007).

Contudo, em muitas situações o planejamento urbano deixa de incluir a arborização como atividade a ser devidamente contemplada e executada nas políticas de desenvolvimento urbano (GONÇALVES et al., 2004). A falta de diretrizes para a arborização permite que iniciativas pontuais e desprovidas de conhecimento técnico introduzam espécies incompatíveis com o ambiente e com os usos sociais e econômicos do espaço urbano em questão.

Essa situação é traduzida na perda da eficácia da arborização em transmitir conforto físico e psíquico, trazendo infortúnios e transtornos, a exemplo de plantios desordenados, resultando

\footnotetext{
${ }^{1}$ Graduada em Geografia (UNISC). vanesilopes@yahoo.com.br

${ }^{2}$ Doutor em Geografia Humana (UFSC). Pós-Doutorado em Geografia e Planeamento Regional pela Universidade Nova de Lisboa. Professor do Programa de Pós-Graduação em Desenvolvimento Regional da Universidade de Santa Cruz do Sul (UNISC).rlls@unisc.br
} 
em distribuição irregular das espécies (YANG et al., 2005; ROSSATTO; TSUBOY; FREI, 2008). A partir dessas considerações, o trabalho que aqui se apresenta, busca identificar os diversos aspectos que envolvem a urbanização e a arborização da via principal da área central da cidade de Santa Cruz do Sul.

A rua Marechal Floriano é considerada a principal via da área central da cidade, pois além de concentrar inúmeros órgãos públicos e estabelecimentos comerciais e de serviços, também serve de ligação entre as zonas sul e norte da cidade. Essa via apresenta ao longo do seu trajeto uma grande concentração de árvores, constituindo um "túnel verde". De fundamental importância para a qualidade ambiental e de vida no meio urbano, a arborização dessa rua ocorreu num contexto de intensa urbanização e de mudanças de uso no espaço central da cidade, refletindo os desafios e as contradições da urbanização, bem como condicionando as políticas de planejamento urbano e ambiental.

Sendo assim, inicialmente o trabalho apresenta como ocorreu o processo de urbanização e arborização em Santa Cruz do Sul buscando entender a transformação do espaço urbano ao longo dos anos e como isso afetou na arborização da cidade. Posteriormente será ilustrado a caracterização da área de estudo bem como uma a análise dos critérios e diretrizes que definiram a arborização da cidade. Por fim, o trabalho apresenta os conflitos e desafios na gestão da arborização na área central de Santa Cruz do sul através das percepções dos atores sociais que ali circulam, trabalham ou residem. Compreender melhor esses processos, suas relações e seus reflexos no desenvolvimento urbano e ambiental da cidade é o principal objetivo dessa análise.

\section{A urbanização e a arborização na via central da cidade de Santa Cruz do Sul: reflexos e contradições}

Um dos temas mais relevantes na atualidade refere-se a questão das áreas verdes e sua importância no contexto dos espaços urbanos. A consolidação contínua dos espaços urbanos marcado em grande parte pelo processo de industrialização do século XX, gerou alterações tanto nos usos quanto na estrutura dos solos urbanos (FRÖHLICH, 2015).

Ao passo que os centros urbanos se desenvolveram com o processo de industrialização, as áreas verdes das cidades adquiriram um novo significado. Analisar as interferências dessa crescente urbanização sobre os espaços das cidades revelam as dinâmicas presentes entre sociedade e natureza na contemporaneidade.

Entre seus mais de 150 anos de história, Santa Cruz do Sul teve um desenvolvimento notável, deixando de ser um pequeno povoado e tornando-se hoje a cidade de maior centralidade econômica e de serviços públicos da região do Vale do Rio Pardo. Contudo, as transformações sofridas no espaço urbano levaram a uma degradação do meio ambiente, substituindo áreas verdes por loteamentos e edifícios em razão da expansão da cidade.

A história de Santa Cruz do Sul inicia-se com a colonização dessas terras em dezembro de 1849 por imigrantes alemães através da política do governo imperial, no século XIX. As terras ocupadas pela colônia de Santa Cruz do Sul foram cedidas aos imigrantes por intermédio da lei de incentivo à imigração estrangeira. A ocupação dessas áreas envolveu também a construção inicial da povoação para ser a sede da colônia em 1855, localizada na época no município de Rio 
Pardo (SILVEIRA, 2003). Os primeiros imigrantes se estabeleceram na Colônia Picada Velha, hoje conhecida como Linha Santa Cruz.

Este período, caracterizou-se pelo desmatamento do lote, pois a natureza predominava na paisagem da época e para tornar o meio habitável os futuros moradores tinham como tarefa inicial limpar a área e erguer suas moradias. O núcleo urbano de Santa Cruz do Sul ocupava uma área de aproximadamente $753.000 \mathrm{~m}^{2}$, de um total de $9.538 .750 \mathrm{~m}^{2}$ comprados pela província para fins da povoação.

A economia da colônia voltava-se somente para o autoconsumo e os produtos agrícolas eram comercializados através da troca, onde os colonos trocavam seus produtos por outros que não possuíam, como o como sal, açúcar, café, vinho e vinagre, não havendo praticamente excedentes (WINK, 2000). Gradativamente ocorreu a substituição da produção de subsistência para outra voltada ao mercado, favorecendo o aumento das exportações.

Nos primeiros anos da década de 1850, os moradores produziam feijão, tabaco, milho, batata, cevada e linho. Uma parte era consumida e outra exportada através do Rio Pardo. Não demorou muito para que o tabaco se tornasse o produto agrícola de maior produtividade, logo o governo da província começou a importar sementes para serem distribuídas. Dessa forma os colonos conseguiram ganhar algum dinheiro e saldar seus débitos sobre a aquisição de terras (PREFEITURA DE SANTA CRUZ DO SUL, 2018).

O comércio começou a estabelecer-se notadamente na sede da freguesia por volta de 1860. "[...] O florescimento do comércio na freguesia, teve como consequência sua independência econômica de Rio Pardo, que passou a perder a exclusividade sobre a circulação de mercadorias na região" (WINK, 2000, p.96).

Em decorrência do aumento de transações comerciais, favorecidas pela diversificação das atividades agrícolas, o núcleo urbano desenvolveu-se ainda mais e em 1877, através da Lei no 1079, a "freguesia de São João de Santa Cruz" recebeu o título de Vila, emancipando-se de Rio Pardo.

Sobre essa questão, Wink (2000, p. 36) expressa que

O progresso da colônia, com sua produção agrícola diversificada, impulsionou o início das exportações, trazendo consequentemente o crescimento do núcleo urbano, que aos poucos começou a concentrar atividades de apoio a produção e a população rural. A partir de 1870, o cultivo do fumo ganha destaque e ao final da década a então Freguesia de Santa Cruz passa a ser denominada de vila, com a instalação da Câmara Municipal em 1878.

Com a emancipação teve início a formação de uma média burguesia local. Alguns agricultores desenvolveram-se economicamente, possuindo assim condições de implantar pequenos comércios. Através do trabalho dos colonos, da acumulação de capital pelos comerciantes bem como a progressiva evolução da infraestrutura de transporte, criou-se também condições adequadas para a instalação de indústrias (SILVEIRA, 2006).

O crescimento da população da vila gerou a necessidade de abertura de novos quarteirões, as edificações de barro e tábuas que predominavam na época aos poucos foram sendo substituídas por construções de alvenaria, evidenciando o desenvolvimento material alcançado por seus moradores (WINK, 2000). Um dos primeiros elementos da infraestrutura a 
ser inserido na cidade foi a iluminação pública, constituída em 1880 por lampiões a querosene, distribuídos ao longo da rua principal (MARTIN, 1982).

A partir de 1890, foram sendo erguidas diversas edificações, e pouco a pouco o centro da cidade foi ganhando forma. O empreendimento mais importante para Santa Cruz na época foi a construção do ramal ferroviário Rio Pardo-Santa Cruz, com uma extensão de $35 \mathrm{Km}$, inaugurada em 19 de novembro de 1905. Desta data em diante, quando também a vila passou a categoria de cidade, uma nova fase de prosperidade passou a vigorar, pois a facilidade nos transportes impulsionou extraordinariamente as exportações.

Conforme Wink (2000), a cidade passou a apresentar um acelerado crescimento populacional, cada vez mais pessoas migravam para o núcleo urbano atraídos pela oferta de trabalho na cidade, favorecida pela intensificação do comércio bem como pela instalação de manufaturas e indústrias. Em 1917 o número de habitantes da área central passou a ser de 3.400 pessoas, indicando um aumento aproximado de $75 \%$ em relação a 1900.

A rua Marechal Floriano, recorte espacial desse estudo, era uma via que apresentava grande concentração de estabelecimentos comerciais. As ruas não eram calçadas e a circulação de veículos era reduzida. A cidade estava em seu desenvolvimento inicial e a área central não apresentava muitas áreas verdes. As Tipuanas, que constituem o túnel verde, ainda não se faziam presentes. Os olhares dos governantes locais miravam a expansão da mancha urbana, não cabendo nesse propósito a arborização.

O processo de urbanização entre 1940 - 1990

Em Santa Cruz do Sul o processo de urbanização foi impulsionado pela produção de tabaco, pois as exportações do produto favoreceram a instalação de importantes equipamentos e das primeiras indústrias na cidade no começo do século XX (WINK, 2002).

Wink (2002) também afirma que o início da transnacionalização do setor agroindustrial fumageiro, após 1965, foi responsável por transformações nas relações de produção, bem como sobre a estrutura física da cidade, trazendo as facilidades geradas pela implantação de uma infraestrutura moderna. Como consequência dessa modernização houve a migração ruralurbana. A população que vinha do campo em busca de melhores condições de vida acabou ocupando os bairros periféricos, resultando na expansão da cidade.

Ao passo que a produção e exportação de tabaco tornou-se mais intensa, Santa Cruz do Sul desenvolveu-se de forma acelerada, passando a concentrar população, equipamentos e serviços (FRÖHLICH, 2015). A infraestrutura implantada criou boas condições para a instalação das primeiras indústrias, tendo como exemplo a British American Tobacco, primeira empresa de capital estrangeiro a se instalar na cidade, em 1917 (WINK, 2000).

A expansão urbana que a cidade apresentou, a partir dos anos da década de 1950, continuou crescente nas décadas posteriores, possibilitando a ligação do centro aos bairros, às rodovias intermunicipais e à sede dos diversos distritos (WINK, 2002).

Nesse período, a área central caracterizava-se pela ocupação residencial e desenvolvimento de várias atividades comerciais, de serviços e industriais. As indústrias também desenvolviam suas atividades nessa área, especialmente na área formada pelas ruas Marechal 
Floriano, Senador Pinheiro Machado, Carlos Trein Filho e Galvão Costa (WINK, 2002). A partir de 1980, segundo Silveira (2006), Santa Cruz do Sul passou por profundas alterações espaciais, entre as quais destacam-se a verticalização do centro e arredores, e expansão do perímetro urbano, que resultou na criação de loteamentos e condomínios fechados, estes, sobretudo a partir dos anos 1990.

Esse processo pode ser explicado, em parte, pela movimentação do capital industrial oriundo da internacionalização do setor fumageiro e desnacionalização das empresas locais, assim como da interação de vários agentes, sobressaindo-se os agentes do mercado imobiliário (OLIVEIRA, 2012).

Analisando as questões apresentadas até o momento, percebe-se que Santa Cruz do Sul em seus primórdios nada mais era que uma pequena colônia rodeada pelo verde da natureza. Aos poucos, com o desenvolvimento de novas técnicas, foi modificando-se para atender as necessidades da economia urbana, capitaneada pela indústria do tabaco. Nesse período, a cidade já apresentava uma clara urbanização e os elementos naturais perderam espaço, restando-lhes apenas praças e algumas ruas.

Todavia, essa situação não perdurou, entre 1940 e 1950 iniciou-se a implantação de espécies arbóreas em uma das vias mais importantes da cidade, a rua Marechal Floriano. Esse fato pode estar associado ao próprio processo de urbanização, que criou a necessidade de espaços para trocas sociais onde as pessoas pudessem se reunir e desfrutar de paisagens naturais agradáveis depois de cansativas jornadas de trabalho ao mesmo tempo que pudessem servir também de atrativo a turistas.

Urbanização e arborização de Santa Cruz do Sul no período contemporâneo

Conforme ilustrado anteriormente, Santa Cruz do Sul teve um crescimento considerável favorecido principalmente pela instalação de seu polo industrial. Ocorre nesse período a intensificação da atividade comercial bem como a instalação de manufaturas e primeiras indústrias (WINK, 2000).

Sendo assim, surge uma maior oferta de trabalho e diversas pessoas oriundas da área rural do próprio município bem como de municípios vizinhos migraram para o centro da cidade, favorecendo o crescimento no número de habitantes. Esse aumento da população urbana de Santa Cruz do Sul ocorreu principalmente entre as décadas de 70 e 80 e criou a necessidade de criação de novos lotes de terra.

A área urbana, a partir de 1977, expandiu-se em todas as direções, acredita-se que esse crescimento esteja ligado a duas causas, a primeira foi a ação da prefeitura com a criação do distrito industrial e a instalação de ruas e vias expressas que ligavam a zona sul da cidade, onde se localizou o novo distrito industrial, e o conjunto da cidade. E a segunda causa da expansão urbana, deveu-se a uma contínua ampliação do perímetro urbano, atendendo o interesse dos proprietários de terras que objetivam a conversão da terra rural em urbana, para poderem auferir maiores ganhos com sua comercialização para fins da criação de novos loteamentos residenciais.

Essa condição associa-se também ao primeiro Plano Diretor de Desenvolvimento Urbano 
de Santa Cruz do Sul, elaborado em 1977 e que teve como objetivo principal, institucionalizar e regular o crescimento espontâneo, visando limitar a expansão desordenada. Da mesma forma, na direção noroeste, o atual bairro Várzea, passa a materializar sua ocupação, efetivando a expansão nas áreas mais próximas ao rio Pardinho. Com isso o crescimento da cidade foi perdendo a forma ortogonal original, com as vias se moldando aos antigos caminhos existentes e a topografia das áreas de expansão (OLIVEIRA, 2017).

Para Silveira (2006) a partir de 1980, Santa Cruz do Sul passou por diversas mudanças espaciais, dentre as quais estão a verticalização do centro da cidade e bairros próximos, bem como a expansão da sua área urbana, consequência da criação de loteamentos e condomínios fechados.

Contudo, através da abertura de novos loteamentos populares, criação de loteamentos fechados e condomínios residenciais de alto padrão, provocou a diminuição das áreas verdes. De 1984 até 2011, a cidade de Santa Cruz do Sul urbanizou-se intensamente através das ações antrópicas, acompanhado pela constante redução das áreas verdes.

A redução de áreas verdes no centro da cidade em 2001, é resultado da viabilização das formas de produção do espaço urbano que levou a um significativo aumento da produção imobiliária. Atualmente a cidade apresenta crescimento na direção norte, onde se localiza o bairro Linha Santa Cruz, nele o que antes era área verde e de cultivo, virou espaço para a construção de loteamentos. Essa situação repete-se no sentido sul, devido a criação de moradias, destinadas em grande parte para a classe operária. Na direção do cinturão verde, o mesmo processo vem ocorrendo, área pela qual apresenta a maioria dos loteamentos e condomínios fechados.

Quanto mais o espaço da cidade expandiu-se, mais as áreas verdes perderam espaço. Nas que ainda restam percebe-se a presença de uma vegetação reduzida. A substituição da cobertura vegetal em busca do "desenvolvimento" resulta em como centros urbanos com temperaturas mais elevadas, causa danos à flora e à fauna, diminui a infiltração do solo, provoca inundações devido na falta de escoamento da água, entre outros problemas (MOTTA, 1997).

Tendo em vista essas questões, tornar o meio urbano mais verde passou a ser uma preocupação para Santa Cruz do Sul. As pequenas mudas implantadas no centro por volta de 1950, atualmente proporcionam uma bela sombra, amenizando o calor intenso dos dias de verão. A paisagem da área central da cidade ganhou mais cor com a implantação das árvores. Apesar disso, a arborização da área central bem como a de outras ruas da cidade, deu-se sem planejamento e com a utilização de espécies exóticas, a exemplo das Tipuana tipu (Benth) Kuntze (tipuana), que formam um túnel verde, atrativo turístico da cidade.

Tendo em vista que uma arborização inadequada pode resultar em problemas para a população e causar danos as próprias espécies arbóreas, os tópicos a seguir apresentam brevemente a área de estudo fazendo uma análise sobre a importância do planejamento para a arborização da cidade bem como buscam identificar quais são as normas que orientaram/orientam a arborização da via central da cidade. 


\section{Caracterização da área de estudo: 0 túnel verde da cidade de Santa Cruz do Sul}

O município de Santa Cruz do Sul, localiza-se na região do Vale do Rio Pardo, na zona de transição entre a encosta inferior do Nordeste e depressão central do estado do Rio Grande do Sul, entre as coordenadas geográficas de 2943'59" de Latitude Sul e 5224'52" de Longitude Oeste (Figura 1).

A região apresenta altitude média de 122 metros acima do nível do mar e clima subtropical temperado, com temperaturas médias de $19^{\circ} \mathrm{C}$, máximas de $42^{\circ} \mathrm{C}$ e mínimas de $5^{\circ} \mathrm{C}$. As chuvas ocorrem em médias de 100 a 126 dias ao ano, com índice de precipitação variando de 1300 a $1800 \mathrm{~mm}$. O município de Santa Cruz do Sul possui área total de 733,409 km² e uma população de 118.374 habitantes (IBGE, 2010).

\section{Figura 1 - Localização de Santa Cruz do Sul}

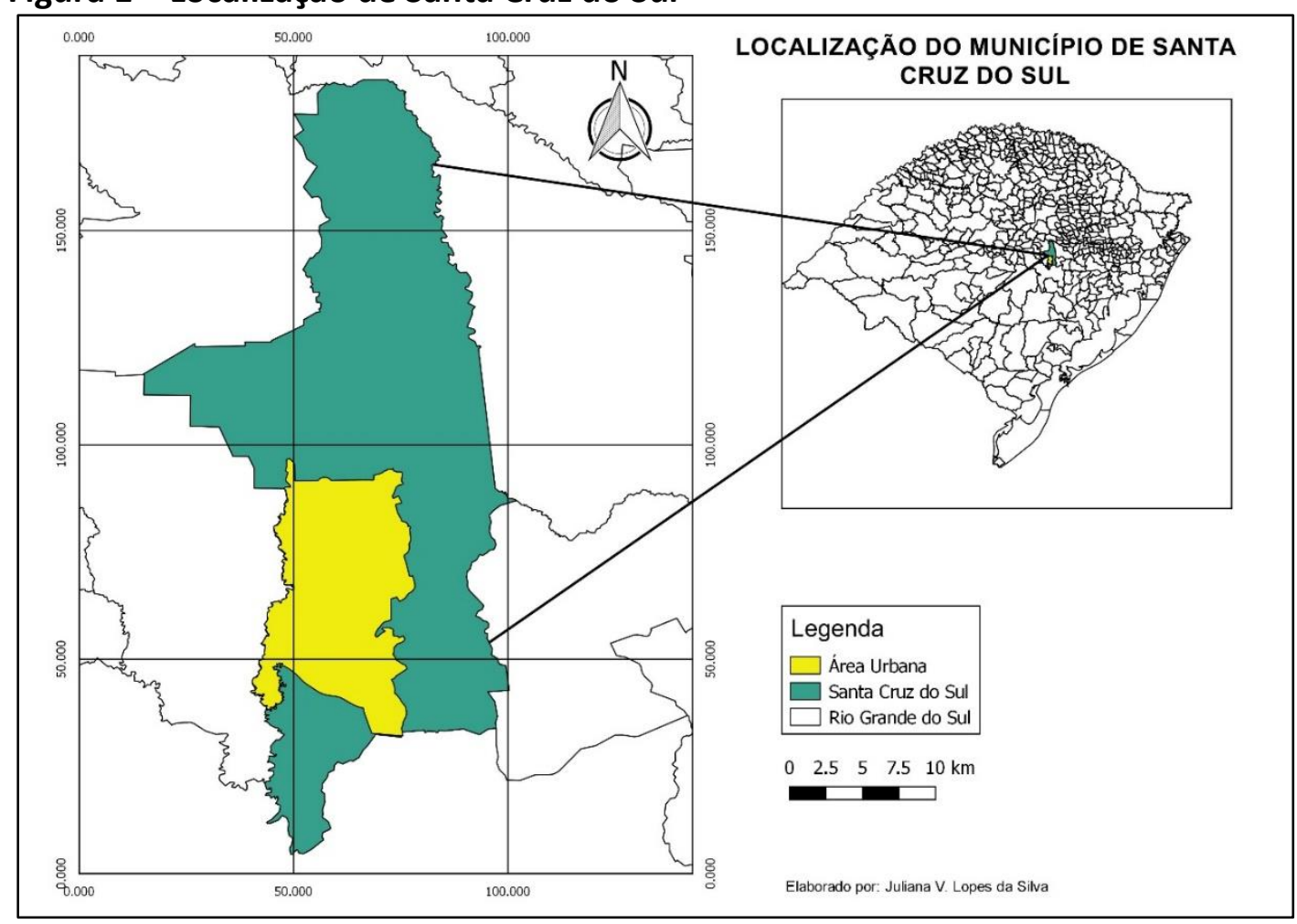

Fonte: elaborado por Juliana V. Lopes da Silva.

O centro da cidade apresenta quadras de característica urbanística similar, com pouca variação de tamanho e grande similaridade arquitetônica, exceto em áreas periféricas da cidade. A região central abriga ainda a Catedral São João Batista, construída em estilo neogótico, com jardim em seu entorno e praças plenamente arborizadas. Também compõe a paisagem urbana um túnel verde que contempla grande parte da Rua Marechal Floriano, via principal da cidade.

O túnel verde possui extensão aproximada de 780 metros. Símbolo da cidade, é constituído por 180 exemplares de Tipuanas, árvores da espécie arbórea da família fabaceae, cujas origens provém da Bolívia e do norte da Argentina. Para a realização do estudo analisouse a área de cinco quadras, na direção sul-norte, tendo como marco inicial o cruzamento da rua Marechal Floriano com a rua Senador Pinheiro Machado, encerrando-se no cruzamento da rua 
Marechal Floriano com a rua Borges de Medeiros, tendo em vista que nesse perímetro o túnel verde apresenta-se mais contínuo e fechado, conforme representa a figura 2.

\section{Figura 2 - Túnel Verde - Santa Cruz do Sul}

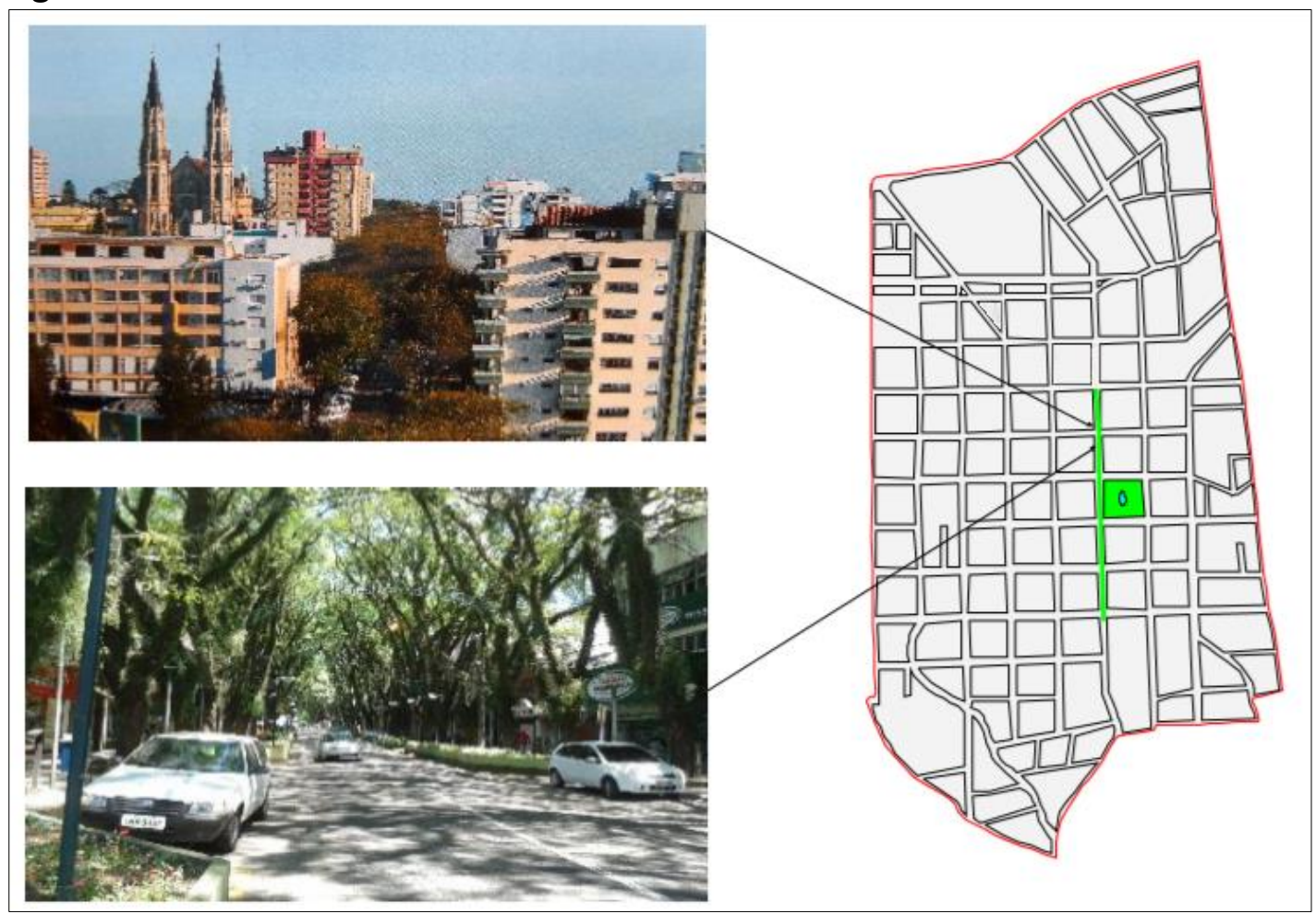

Fonte: elaborado por Gabriel A. Santos (2015).

As árvores, que possuem aproximadamente 70 anos, abrangem a área de diversos pontos comerciais e estabelecimentos de serviços públicos e privados mais procurados.

De modo geral nessa rua o comércio é predominante. As pessoas que ali residem são as que mais usufruem dos benefícios da presença da arborização. Todavia, existe uma grande polêmica em relação a permanência das árvores no local, o que gera opiniões divergentes entre os santa-cruzenses. Ao mesmo tempo em que ostentam beleza e amenizam o calor nos dias de verão por meio da sombra, suas raízes danificam calçadas e canteiros, dificultando o tráfego das pessoas, provocando até mesmo acidentes.

A resolução dos problemas em relação a arborização cabe ao próprio município e começa pela construção de um planejamento adequado. Ações como o monitoramento de problemas decorrentes do plantio de árvores, bem como a própria educação ambiental dos cidadãos para valorização e preservação das áreas verdes são fundamentais para estabelecer certo equilíbrio e evitar possíveis problemas. É a partir dessas questões que emerge o foco deste trabalho.

\section{Planos Diretores e Legislação Municipal de Santa Cruz do Sul - Critérios e diretrizes da arborização urbana}

Grande parte das cidades brasileiras originaram-se de maneira espontânea, sem qualquer planejamento prévio. Na medida em que foram surgindo demandas espaciais e infraestruturais, 
sobretudo durante o processo de urbanização em que muitas pessoas migraram do campo para as cidades, o espaço urbano foi moldando-se e expandindo-se para suportar a massa populacional que cada vez mais aumentava.

Contudo, esse fato provocou o surgimento de diversos problemas no âmbito organizacional e ambiental. Para auxiliar e orientar os agentes responsáveis pelo planejamento das cidades, desenvolveram-se algumas ferramentas importes, dentro dessas ferramentas está o Plano Diretor, que norteia a política de desenvolvimento das cidades.

O Plano Diretor consiste em um conjunto de princípios e regras orientadoras da ação dos agentes que constroem e utilizam o espaço urbano (BRASIL, 2002). O objetivo central do Plano Diretor é construir cidades com qualidade para todos, impedindo a formação de assentamentos irregulares e informais.

O primeiro Plano Diretor da cidade de Santa Cruz do Sul data de 1976. Na análise que se realizou sobre o primeiro Pano Diretor da cidade, nota-se uma clara preocupação com a delimitação física dos espaços. O documento apresenta, em grande parte, normas sobre o uso do solo e edificações dos espaços, evidenciando preocupação em organizar as áreas da cidade que cada vez mais ganhava dimensão.

No aspecto ambiental, o plano aborda apenas os impactos das atividades das industriais sobre a saúde dos habitantes. As definições sobre a preservação ambiental se resumiam em apenas um artigo, sendo esse o Art. 38, sendo assim, as questões ambientais eram abordadas de maneira geral e a arborização urbana não possuía nenhuma legislação específica.

Com o passar do tempo surgiram outras necessidades em relação ao planejamento, principalmente sobre as questões ambientais. A partir disso, em 12 maio do ano de1993, foi criada a Lei Ordinária 2473 que institui o Conselho Municipal do Meio Ambiente. Dentre os objetivos do conselho estão a função de decidir questões sobre a política municipal do meio ambiente, avaliando e propondo leis e medidas que prezem pela utilização e conservação dos recursos naturais para a atual e futuras gerações, incentivar a educação ambiental em todos os níveis de ensino, incentivar a integração com a universidade e associações civis no sentido de instituir pesquisas que venham a garantir e aprimorar o controle da poluição, dentre outras definições (essa lei foi alterada pela Lei $N^{0} 7.284$ de 20 de maio de 2015).

Devido à grande importância que a arborização passou a assumir dentro dos espaços urbanos ao contribuir para o equilíbrio ambiental e melhoria da qualidade de vida da população, fez-se necessário a criação de uma legislação para orientar e normatizar ações de manejo, plantio e conservação das espécies arbóreas.

Em função disso, em 30 de novembro de 2001, instituiu-se no Município de Santa Cruz do Sul o Projeto de Lei № 122/E/2001, aprovado no dia 07 de janeiro de 2003, que estabelece normas de manejo, proteção e conservação da arborização. Dentre algumas definições presentes no projeto, consta o Art. 4 ㅇ do capítulo I, onde define-se que a Prefeitura Municipal é o órgão responsável pelo controle ou execução da implantação, manutenção bem como a remoção de árvores e arbustos localizados na área urbana.

Os Art. 5 e 6ㅇ definem a Secretaria Municipal de Transportes e Serviços Públicos como encarregado pelas intervenções na vegetação arbórea e arbustiva existente nas áreas pertencentes ao Município. Através de seu Departamento de Meio Ambiente (DEMA) torna-se 
responsável também pelas avaliações técnicas necessárias para o manejo correto das vegetações arbórea e arbustiva.

O capítulo III da referida lei disserta sobre as intervenções de poda e corte raso, sobre essa questão o Art. 15 dispõe o que corte raso de árvores e arbustos em áreas pertencentes ao município, somente poderá ser autorizado nos seguintes casos:

\footnotetext{
I - quando a árvore chegar ao fim da sua vida útil ou estiver fortemente desvitalizada;

II - defronte a terrenos a serem edificados, quando o corte for indispensável à realização da obra;

III - quando a árvore apresentar risco iminente de queda;

IV - quando a árvore estiver causando relevante dano ao patrimônio público ou privado; $V$ - quando a espécie estiver em local inadequado as suas características, e não exista alternativa adequada para sua permanência;

VI- para desbaste de conjuntos plantados com espaçamentos reduzidos, visando evitar excessos de umidade, excessiva escuridão nos períodos noturnos ou expressivos problemas à visualização de atividades comerciais. (LEI MUNICIPAL № 122/E/2001).
}

$\mathrm{O} \S 2^{\circ}$ do mesmo capítulo fala especificamente sobre as podas e cortes da espécie exótica tipuana (Tipuana tipu), onde definiu-se que essa espécie deverá ser gradualmente substituída por outras espécies, quando situada sob fiação aérea e em calçadas menores que 3,0 metros mesmo não havendo fiação no local.

Posteriormente a isso, em 2007 é elaborado o novo Plano Diretor de Desenvolvimento Social e Urbano do Município de Santa Cruz do Sul, através da lei complementar № 335, de 03 de janeiro de 2007. No Plano Diretor de 2007 a questão da arborização urbana não é abordada. O plano em suma, tem como objetivos regular e ordenar a ocupação do solo, a expansão urbana e a preservação ambiental bem como estabelecer diretrizes para a regulamentação de atividades e do desenvolvimento social.

Na parte ambiental, localizada na seção II do capítulo II, a questão abordada refere-se a ocupação do solo da chamada Macrozona de Preservação Ambiental (MP) que constitui-se de todas nas áreas urbanas das Sedes, das Sedes Distritais, em que devido as condições de solo, declividade, sistema hídrico, instabilidade geológica e tipo de vegetação, ficam sujeitas a restrições quanto a sua ocupação.

Após esse ano, em 2008 foi elaborado o Projeto 07/E/2008, aprovado em fevereiro de 2008. O projeto altera e acresce dispositivos na Lei no 3.127, de 30 de dezembro de 1997 que cria Secretaria Municipal de Meio Ambiente e Saneamento (SEMASS). Como a lei de 1997 foi uma lei sugestão, ou seja, não foi aprovada, pode-se dizer que a SEMASS é oficialmente criada em 2008. Com o surgimento desse órgão as questões ambientais passaram a ser tratadas individualmente.

Dentre as diversas funções da SEMASS estão fiscalizar o cumprimento das normas referentes a meio ambiente, realizar estudos e a proposição das diretrizes municipais, criar normas e padrões relativos à preservação e à conservação de recursos naturais e paisagísticos do município, manter a conservação e a manutenção de parques, praças e jardins públicos e a execução de planos de arborização e implantação da arborização em geral, bem como a conservação do Cinturão Verde e implementação de políticas de incentivos (PREFEITURA MUNICIPAL DE SANTA CRUZ DO SUL, 2008). 
Em setembro de 2011, foi elaborado o Projeto de Lei № 100/E/2011, que trazia em sua redação uma proposta de instituição do Plano Diretor de Arborização bem como normas para manejo e conservação das espécies. Mas essa proposta foi prejudicada pois, apresentava praticamente as mesmas definições, com exceção da implantação do plano diretor, que o projeto apresentado e aprovado em 2001, portanto, não seguiu adiante.

Como a proposta de criação do Plano Diretor de Arborização contida no projeto de lei em 2011 não pode prosseguir, em 4 de janeiro de 2012 foi criado então a Lei № 6.447. Essa lei além de definir normas de manejo, proteção, conservação da vegetação, arborização e procedimentos para corte, transplante ou podas de árvores, institui pela primeira vez um Plano Diretor de Arborização no município.

Uma das primeiras definições que constam na lei é a conceituação do Plano Diretor de Arborização. Conforme a lei, esse plano a ser definido como instrumento de planejamento municipal para a implantação da política de plantio, preservação, manejo e expansão da arborização em áreas públicas na cidade.

No parágrafo único do capítulo I, que disserta sobre as disposições preliminares, definiuse a Secretaria Municipal de Meio Ambiente e Saneamento (SEMMAS) como órgão ambiental responsável pelo licenciamento do plantio, transplante, poda e/ou retirada de vegetação nativa.

O Art. $8^{\circ}$ do capítulo IV, define os objetivos do Plano Diretor de Arborização os quais são

\footnotetext{
I - definir as diretrizes de planejamento, implantação e manejo da Arborização Urbana; II - promover a arborização como instrumento de desenvolvimento urbano e qualidade de vida;

III - implementar e manter a arborização urbana visando a melhoria da qualidade de vida e o equilíbrio ambiental, sempre observando critérios de segurança e preservação do Patrimônio do Município e dos Munícipes de Santa Cruz do Sul; e

IV - integrar e envolver a população, com vistas a manutenção e a preservação da arborização urbana (LEI MUNICIPAL № 6.447/2012).
}

Ficam definidos também normas sobre a distância que os exemplares arbóreos devem ter entre os elementos da cidade e entre os mesmos. A definição dos espaçamentos é necessária pois esta norma garante um bom crescimento do exemplar arbóreo sem causar danos ao ambiente onde serão introduzidas tendo em vista que as árvores aumentam suas dimensões ao longo do tempo.

Há ainda nessa mesma legislação uma relação entre as espécies com uso restrito ou proibido na cidade, apresentado na tabela 1 a seguir. 
Tabela 1 - Espécies com uso restrito ou proibido na arborização urbana, principalmente no passeio público

\begin{tabular}{l|l|l|l|l}
\hline NOME COMUM & NOME CIENTÍFICO & USO & LOCAL & ORIGEM \\
\hline Canela-tempero & Cinnamomum zeylanicum & Proibido & Passeio público & Exótica \\
\hline Cinamomo & Melia azedarach & Proibido & Passeio público & Exótica \\
\hline Eucalipto & Eucalyptus spp & Proibido & Passeio público & Exótica \\
\hline $\begin{array}{l}\text { Figueira-benjamin } \\
\text { fícus }\end{array}$ & Ficus benjamina & Proibido & Passeio público & Exótica \\
\hline Ingá & Inga spp. & Proibido & Passeio público & Nativa \\
\hline Ligustro & Ligustrum sp & Proibido & Passeio público & Exótica \\
\hline Pinus & Pinus spp. & Proibido & Passeio público & Exótica \\
\hline Tipuana & Tipuana tipu & Proibido & Passeio público & Exótica \\
\hline Tuia Fam. cipreste & Cupressaceae & Proibido & Passeio público & Exótica \\
\hline Uva-do-japão & Hovenia dulcis & Proibido & Todo & Exótica \\
\hline Fonte: file://D:/Lis/Anos\%20lei\%206447.pdf & &
\end{tabular}

Fonte: file://D:/Leis/Anexos\%20lei\%206447.pdf

Todas as árvores listadas na tabela têm o uso classificado como proibido, mas encontramse presentes nos espaços da cidade, bem como em passeios públicos, a exemplo das tipuanas, árvores exóticas que compõe o túnel verde. O Plano Diretor de Arborização Urbana prevê erradicação desta espécie no município (LEI MUNICIPAL № 6.447/2012).

Contudo, em entrevista concedida a pesquisa, a bióloga da SEMMAS afirmou que "as tipuanas foram trazidas porque na época quem trouxe pra cá pensou que ela se adaptava bem a rede elétrica, nesse sentido a pessoa na época tinha razão, mas não consideraram o tamanho da raiz ou nem se sabia disso, não se imaginava que a cidade iria se desenvolver tanto."

Pelo fato do plantio das tipuanas dar-se muitas décadas antes da criação da norma, em uma época em que nem ao menos planejou-se o plantio, tem-se um grande impasse, o que será feito após o fim da vida útil das árvores?

Quando questionada sobre o futuro das tipuanas do túnel verde a bióloga respondeu que no momento não serão plantados nenhum exemplar. Como essas árvores foram plantadas muito próximas, conforme vão sendo retiradas por algum motivo (riscos de cair, muito danificadas, estado fitossanitário precário, etc.) acabam tendo o espaço necessário. Visões futuras sobre o túnel verde ainda não foram discutidas, atualmente os esforços dão-se no sentido de preservar a espécie devido ao grande valor histórico que elas representam para a cidade.

Ainda sobre o Plano Diretor de Arborização, o Art. 18 do capítulo VI define que a autorização para a eliminação de árvores no passeio público depende da análise técnica da SEMMAS, que levará em consideração critérios como o risco de queda, danos ao patrimônio público ou privado, estado fitossanitário precário sem condições de recuperação, adequação de espaçamento através de desbaste de conjuntos plantados com espaçamentos reduzidos, casos comprovados de reações alérgicas provocadas pelo vegetal, dentre outras questões.

Todavia, como toda a regra há exceções, o Art. 27 do mesmo capítulo, impõe que qualquer árvore pode ser considerada imune ao corte, dependendo de critérios como por exemplo a localização, raridade, antiguidade, interesse histórico, valor científico ou paisagístico etc. (LEI MUNICIPAL № 6.447/2012). 
Atualmente está em processo de elaboração o novo Plano Diretor, no entanto, assim como os demais planos diretores elaborados até o momento, sua função é regular os usos do solo e não aborda questões sobre a arborização, sendo assim essa função é exclusiva do plano diretor de arborização existente no município. Desenvolver uma legislação específica para a arborização da cidade representa um grande avanço sobre as questões ambientais tendo em vista a importância dessa no meio urbano.

Em linhas gerais, as características mais marcantes a serem observadas na legislação municipal de Santa Cruz do Sul sobre a questão ambiental, mais especificamente sobre a arborização urbana, é a evolução apresentada. De um Plano Diretor que continha apenas um artigo sucinto sobre preservação ambiental passou-se à um planejamento urbano exclusivo para a arborização urbana. Esse fato explica-se pelas transformações ocorridas na sociedade a partir do processo de urbanização e industrialização sofridos. O verde que antes "atrapalhava" a formação das cidades hoje integra os espaços urbanos proporcionando bem-estar e equilíbrio ecológico.

\section{Conflitos e desafios na gestão da arborização na área central da cidade de Santa Cruz do Sul: as percepções dos atores sociais}

As cidades de hoje são o resultado de processos históricos, épocas, costumes, culturas e povos diversos, que paulatinamente foram deixando marcas no desenho urbano. De pequenos e primitivos aglomerados, hoje ostentam grandes projetos arquitetônicos, resultado das descobertas de novas técnicas atreladas ao desejo humano em "melhorar" o meio em que vive.

Todavia, a grande concentração de edificações de diversos pavimentos nas cidades gera uma maior absorção da radiação solar e favorece o surgimento das chamadas ilhas de calor, fenômeno climático que ocorre principalmente nas cidades com elevado grau de urbanização, em que há grande presença de construções e poucas ou nenhuma área verde, ocasionando o aumento da temperatura desses locais em relação as demais áreas do entorno.

Nesse sentido as árvores assumem importante papel, pois proporcionam a redução do calor através da sombra de seus galhos e folhas. Analisando a relação da arborização com a cidade de Santa Cruz do Sul, nota-se que esta é uma cidade arborizada, apresentando expressiva vegetação nativa em seus arredores, conhecida como "cinturão verde", área de preservação da flora e fauna da região e conservação de importantes nascentes. A cidade apresenta ainda áreas públicas, praças e uma política de arborização responsável por controlar a manutenção e conservação das espécies arbóreas.

Presente no coração da cidade, encontra-se um formoso túnel verde, composto por 180 exemplares da espécie Tipuana tipu, inseridos na rua Marechal Floriano por volta de 1950. Sua ocorrência natural origina-se da região localizada ao Sul da Bolívia e norte da Argentina (LORENZI, 2003, MAINIERI, 1989). É encontrada na arborização urbana nos estados das regiões sul e sudeste brasileiras e nos países Argentina, Bolívia, Chile, França, Estados Unidos e Argélia (LORENZI 2003; MACAYA, 1999 apud BRAZOLIN, 2009; MAINIERI, 1989; TORTORELLI, 1956).

O túnel verde, símbolo de natural da cidade, no entanto, não é percebido do mesmo modo por quem mora, trabalha ou apenas circula pela rua. Ao passo que embeleza os espaços e 
contribui ambientalmente, provoca discórdia entre habitantes, pois para muitos, elas são sinônimo de desastre e sujeira.

Diante disso, percebe-se o planejamento da arborização como ferramenta essencial para prevenir/amenizar possíveis problemas. Árvores são seres vivos, portanto possuem um ciclo. Crescem, se desenvolvem e morrem como qualquer ser, e, portanto, necessitam de certos cuidados. Quando não recebem os devidos cuidados revoltam-se e provocam sérios problemas.

Partindo dessas questões, pretende-se aqui analisar as diversas percepções dos atores sociais visando entender como a arborização interfere na vida urbana bem como compreender a essência das causas, a partir da própria percepção das pessoas que fazem o uso de forma direta e indireta do meio em estudo.

Para a coleta das informações realizou-se entrevistas com algumas pessoas que circulam ou residem na via principal da cidade, mais especificamente no perímetro do túnel verde. Foram entrevistados no total dez pessoas, dentre elas, três moradores, três lojistas e quatro pessoas que ali circulam, na faixa etária de 30 e 70 anos. Os entrevistados foram escolhidos aleatoriamente em pontos espalhados no perímetro do túnel verde.

Iniciando o diálogo com as pessoas que ali circulam, foram entrevistados dois moradores de áreas próximas a via estudada, e dois visitantes de outra cidade. Na visão dessas pessoas as árvores só proporcionam beleza e agregam verde a cidade, não atrapalham em nada e ainda proporcionam uma sombra agradável nos dias quentes.

Dentre os comerciantes/lojistas que possuem seus estabelecimentos dentro do túnel verde, deu-se preferência na pesquisa para os mais antigos visto que estes estão há mais tempo em contato com as árvores e puderam acompanhar mais o desenvolvimento dos exemplares do que os comerciantes recentes.

Ao serem questionados sobre o seu ponto de vista em relação às tipuanas, as respostas foram diversas. $O$ comerciante $A$ que possui há cerca de 25 anos de comércio no local afirmou não ter nada a reclamar. Nas palavras do entrevistado as árvores são simplesmente fantásticas e devem ser preservadas pois fazem parte da história da cidade.

Já o comerciante $B$, que informou ter seu estabelecimento há cerca de 45 anos, quando questionado sobre a sua opinião, disse ter problemas com a sua calçada que constantemente precisa de reparos devido aos estragos ocasionados pelas raízes das árvores, mas mesmo assim admite que as árvores deveriam ser preservadas.

O comerciante $\mathrm{C}$, que possui seu estabelecimento há mais de 30 anos, relatou ter problemas com a calçada, segundo ele, "está uma esculhambação, não adianta arrumar", e com as folhas em frente ao estabelecimento que geram muita sujeira. Expressou também que a prefeitura deveria fazer a manutenção constante das árvores e se necessário retirar as que apresentam problemas e trocar por outras que danificam menos as calçadas.

Para os moradores o problema é agravado. Quando perguntados sobre como avaliam a arborização da cidade, se essas árvores atrapalham ou não seu dia-a-dia notou-se que todos relataram ter problemas com a arborização da via.

Dentre os problemas relatados, o morador A informou que os galhos são o que mais incomodam, por estarem podres costumam cair e provocar danos a seu telhado. Informou que devido a isso teve muitos gastos colocando telhado novo e a cada chuva ele fica preocupado com 
o fato de poder cair um galho e ele acabar perdendo seus bens. Disse ainda que esse problema intensifica-se no inverno, período em que as chuvas e ventanias ocorrem com maior frequência, além disso as folhas que caem entopem a calha e a água escorre por tudo.

O morador $\mathrm{B}$ falou que além de ter problemas com os galhos das árvores e folhas também, as rachaduras causadas no seu apartamento são terríveis. Conforme relatos ele já realizou os concertos, mas os danos continuam aparecendo.

$\mathrm{O}$ morador $\mathrm{C}$ informou ter os mesmos problemas que os outros moradores e solicitou à prefeitura que resolvesse essa questão antes que as árvores prejudicassem seriamente alguém.

Analisando as entrevistas percebe-se que quanto mais a pessoa convive no espaço onde estão as árvores, mais problemas elas percebem. Os visitantes somente veem a beleza que o túnel verde representa para a cidade, os comerciantes enfrentam problemas com as calçadas e a sujeira, mas mesmo assim reconhecem a importância dessas árvores já os moradores dos prédios da via, em grande parte sentem-se incomodados e até prejudicados devido ao estado de conservação das tipuanas. A partir das entrevistas fica evidente a divergência de opinião, ilustrando a existência de um conflito entre os agentes sociais.

Sobre a situação das calçadas e das árvores o ex-vereador e ex-secretário do meio ambiente, o Sr. Alberto João Heck também entrevistado, explicou que por característica da própria espécie e por uma questão de sustentação da planta, as raízes das árvores estendem-se na mesma proporção dos galhos e acabam quebrando as calçadas devido à dimensão radicular. A prefeitura exige da população a manutenção das calçadas, no entanto acaba agravando o problema pois, por falta de opção e para se adequarem à legislação, muitas vezes simplesmente cortam as raízes aparentes para deixar a calçada em nível plano.

Esse ato resulta no apodrecimento das as árvores e perda de sustentação. Segundo o exvereador a manutenção das calçadas dessa via não deveria ser feita pela população e sim pela prefeitura por julgar terem os materiais adequados para a intervenção bem como o conhecimento técnico necessário.

Alberto em crítica aos conflitos existentes expressa que "Um quer sombra, o outro não quer folha, o outro não quer raízes incomodando na calçada, então a solução seria colocar árvores de metal, com folhas de plástico! Fica verdinho, dá para trocar. As pessoas querem ter árvores, mas não querem ter sujeira no chão."

Sobre essa afirmação cabe a pergunta: como satisfazer a todos sem prejudicar também os exemplares arbóreos símbolo da cidade? Não se tratam de quaisquer espécies, mas sim elementos que fazem parte da essência da cidade há 70 anos.

O Sr. Alberto Heck contou que defendia um processo de revitalização do túnel verde, e ao falar de uma revitalização e possível necessidade de substituição dos exemplares foi muito criticado. Porém, analisando a situação atual das árvores fica evidente a necessidade de intervenção.

Devido as frequentes polêmicas e transtornos em relação as árvores e levando em consideração a sua importância para a cidade surgiram diversos debates sobre o tema visando amenizar os problemas apontados pela população e manter a conservação do túnel verde.

A exemplo desses esforços, em 2014 a prefeitura de Santa Cruz do Sul encaminhou um projeto de lei à Câmara de Vereadores solicitando a realização de um levantamento sobre as 182 
árvores da espécie que existiam na época ao longo da rua Marechal Floriano. O projeto foi aprovado e realizado através das empresas Gabriel Berger - Assessoria e Projetos Ambientais e Reflorest - Reposição Florestal e consistia em um estudo sobre as condições fitossanitárias e estruturais das tipuanas que formam o túnel verde. O projeto resultou em um relatório técnico contendo informações sobre a saúde, risco de queda, estabilidade e convivência com o meio urbano de cada espécie.

No projeto constatou-se a presença de 180 exemplares, dois a menos do que existiam antes do início do projeto. No levantamento realizado foram identificados diversos problemas que podem oferecer riscos à população ou prejuízos aos cofres públicos e/ou privados.

O problema mais encontrado, totalizando $25 \%$, foi a inadequação em relação aos canteiros. O relatório aponta que canteiros adequados proporcionam um melhor desenvolvimento das árvores, o que talvez reduziria o afloramento de raízes nas vias e calçadas. A presença de galhos secos (24\%) e o afloramento das raízes (16\%) foram outros grandes problemas encontrados.

As cavidades no tronco representam $14 \%$ dos problemas. Em muitos casos as cavidades são originadas por um manejo inadequado, como por exemplo, podas mal executadas. Das 180 árvores que compõe o túnel verde, mais da metade, ou seja, 96 árvores apresentam cavidade. Essas cavidades, ou aberturas, são a porta de entrada para que organismos deteriorem o interior das árvores e consequentemente causarem um risco ainda maior de queda.

De acordo com informações do relatório, apesar dos problemas encontrados o estado fitossanitário das árvores está satisfatório, pois há um reduzido índice de espécimes condenados. Com isso, a grande maioria dos indivíduos analisados não necessitam de intervenções de controle, somente em casos de riscos evidentes.

Todavia, o relatório mostra ainda que devem ser realizadas algumas adequações e ressalvas para não comprometer o estado fitossanitário futuro das árvores e a segurança pública, tais como realizar podas e retiradas de galhos secos, adequar os canteiros, realizar adequações dos estacionamentos de carga e descarga, fazer o controle de formigas e cupins, adequar a fiação elétrica, fazer o manejo técnico das raízes que estão aflorando nas calçadas, ruas e nos canteiros, entre outras.

O estudo realizado teve grande importância, pois enfatiza o fato dessas árvores merecerem atenção, bem como a execução de um bom plano de manejo para que se possa estender a vida útil das árvores. Em continuidade aos esforços passados, está em andamento a execução de um programa denominado Programa de Remediação de Risco Iminente e Poda de Limpeza das árvores da espécie Tipuana Tipu (Benth.) Kuntz que formam o túnel verde no Município de Santa Cruz do Sul. Trata-se de um programa técnico de preservação da arborização urbana que forma o Túnel Verde de Santa Cruz do Sul, incluindo avaliação técnica de cada árvore e programa de manutenção permanente para os próximos anos.

Em suma os objetivos do programa são promover a segurança da população que transita pelo Túnel Verde, e promover a revitalização do túnel verde e ampliar o ciclo de vida das árvores. Para isso serão feitas avaliações das ramificações secas e posterior remoção de galhos secos/podres/ocos, quando for o caso, e do estado fitossanitário das árvores, removendo 
vegetação associadas a estas que estiverem em excesso e que estejam prejudicando a vitalidade das árvores.

Os estudos realizados sobre o tema, bem como os demais projetos representam o empenho por parte dos órgãos municipais em encontrar uma solução acerca dos problemas que envolvem a arborização da cidade. Apesar dos conflitos existentes é inegável os benefícios que as árvores trazem ao meio urbano e ao bem-estar da população. Nesse sentido é dever das autoridades realizar a manutenção e conservação dos exemplares arbóreos e dever da população auxiliar na preservação destas para que se possa estender ao máximo a vida útil desse patrimônio natural, visando uma cidade mais sustentável, onde natureza e sociedade possam conviver harmoniosamente.

\section{Conclusão}

As cidades desde seus primórdios até os dias atuais são a representação mais clara das transformações sofridas pela humanidade. A descoberta de novas técnicas foi proporcionando ao homem um modo de usufruir cada vez maios do meio onde vive. Nesse processo de transformação, na medida em que as cidades foram assumindo maiores dimensões, o meio natural foi perdendo espaço.

Impulsionadas pelo processo de industrialização que possibilitou a geração de emprego para muitas pessoas, o meio urbano passou atrair pessoas que viviam no meio rural. Começouse nesse momento também o processo de urbanização onde as cidades passaram a crescer e abrigar um maior número de pessoas.

Todavia, para abrigar essa massa populacional que cada vez mais migravam para o meio urbano tornou-se necessário a criação de novos lotes de terra. O solo passou a ser parcelado, onde antes eram áreas verdes, tornaram-se locais para futuras moradias. $O$ desenvolvimento das cidades deu-se em detrimento do meio natural. Atualmente pouco resta do que um dia foram densas florestas.

$\mathrm{Na}$ busca por tornar o meio urbano mais acolhedor, as árvores tornam-se importante ferramenta pois suas folhas e galhos contribui para o microclima, amenizando o calor intenso nos dias de verão, contribuem para a purificação do ar, embelezam o meio urbano dentre outros benefícios. A partir das questões apresentadas nesse estudo percebe-se a importância assumida pela arborização no contexto das cidades. Na cidade de Santa Cruz do Sul, a presença do túnel verde coloca-se como divisor de opiniões entre os agentes que ali vivem, residem e circulam. Para uns ela causa incômodos, para outros ela é símbolo de beleza.

As tipunanas da rua Marechal Floriano fazem parte da cidade a cerca de 70 anos. Através da análise da legislação da cidade verificou-se que a espécie exótica tem seu uso proibido na arborização de vias públicas, no entanto, devido a seu tempo de permanência na área central da cidade, removê-la ou substituí-las no momento está fora dos objetivos dos responsáveis. Os esforços realizados são no sentido de preservar esse patrimônio natural, mesmo que essa espécie não seja a mais adequada e devido a isso provoque problemas como queda de galhos e danos estruturais. Nesse sentido coloca-se a importância do planejamento da arborização de qualquer espaço, pois esse minimiza ou anula quaisquer chances de problemas futuros. 
Contudo, as árvores em questão, não tiveram um planejamento, foram introduzidas em uma época em que a população não se preocupava com essas questões, a espécie foi trazida a um habitat totalmente inadequado ao seu desenvolvimento e consequentemente reagiu a isso, crescendo e fazendo seu próprio espaço por debaixo das calçadas e entre a rede elétrica.

O planejamento é o passo inicial para toda ação, planejar é pensar, analisar antes de executar. Apesar das tipuanas não terem um planejamento prévio adaptou-se ao meio como pôde. Agora, faz parte da cidade e apresenta inegável beleza.

O túnel verde de Santa Cruz do Sul é um exemplo de integração das áreas verdes com a sociedade. Tornar o espaço urbano mais acolhedor, agradável e atraente aos olhos através de uma arborização adequada traz benefícios à população. As cidades precisam desses espaços, as áreas verdes devem fazer parte da cidade e não removidas da cidade.

Sem elas a única sombra existente é a das próprias edificações que não purificam o ar, que não contribuem ao microclima, que não abrigam a fauna, enfim, que não trazem suavidade os rígidos traços urbanos. Pensar espaços mais verdes tem sido um desafio as cidades, mas introduzi-los no meio urbano é o primeiro passo para torna-las mais sustentáveis, onde sociedade e natureza possam estar integradas.

\section{Referências}

BEISE, M. et al. Relatório sobre a avaliação das árvores da espécie Tipuana Tipu (Benth.) Kuntz que formam o túnel verde no Município de Santa Cruz do Sul. Santa Cruz do Sul. 2015.

BRASIL. Estatuto da Cidade: guia para implementação pelos municípios e cidadãos. 2 ed. Brasília: Câmara dos Deputados, Coordenação de Publicações, 2002.

. Ministério do Meio Ambiente. Resolução Conama 369/2006. Disponível em:

<http://www.mma.gov.br/port/conama/legislacao/CONAMA_RES_CONS_2006_369.pdf.> Acesso em: 23 mar. 2018.

BRAZOLIN, S. Biodeterioração, anatomia do lenho e análise de risco de queda de árvores de tipuana, Tipuana tipu (Benth.) O. Kuntze, nos passeios públicos da cidade de São Paulo, SP. 2009. 265 p. Tese (Doutorado em Recursos Florestais) - Escola Superior de Agricultura "Luiz de Queiroz". Universidade de São Paulo, Piracicaba, 2009.

FEE. Perfil Sócio econômico dos Municípios. Disponível em:

<http://www.fee.rs.gov.br/perfilsocioeconomico/municipios/detalhe/?municipio=Santa+Cruz+ do+Sul>. Acesso em: 19 set. 2017.

FRÖHLICH, C. P.; Loteamentos e condomínios fechados na cidade média de Santa Cruz do SulRS: uma análise sobre a constituição das áreas verdes. 2015. Dissertação. (Mestrado em Desenvolvimento Regional) - Programa de Pós-Graduação em Desenvolvimento Regional, Universidade de Santa Cruz do Sul, Santa Cruz do Sul.

GONÇALVES, W.; PAIVA, H. N. Árvores para o ambiente urbano. Viçosa: Aprenda Fácil, 2004. 242 p. (Coleção Jardinagem e Paisagismo, 3).

IBGE - Instituto Brasileiro de Geografia e Estatística. Cidades. 2010. Disponível em: <https://cidades.ibge.gov.br/brasil/rs/santa-cruz-do-sul/panorama>. Acesso em: 10 ago. 2017. 
LORENZI, H. Árvores exóticas no Brasil: madeira, ornamentais, e aromáticas. Nova Odessa: Instituto Plantarum de Estados de Flora, 2003. 382 p.

McHALE, M. R.; McPHERSON, E. G.; BURKE, I. C. The potential of urban tree plantings to be cost effective in carbon credit markets. Urban Forestry and Urban Greening, v.6, p.46-60, 2007.

MAINIERI, C.; CHIMELO, J.P. Fichas de características das madeiras brasileiras. São Paulo: IPT, 1989. $432 \mathrm{P}$.

MARTIN, Hardy Elmiro. Iluminação Pública. Gazeta do Sul, Santa Cruz do Sul, 7 dez. 1982A, p.3.

MOTTA, Ronaldo Serôa da. Desafios Ambientais da Economia Brasileira. Rio de Janeiro, ago. 1997. Disponível em: <http://www.plataformademocratica.org/Publicacoes/1387.pdf>. Acesso em: 23 mar. 2018.

OLIVEIRA, G. A. S. de. A verticalização urbana em cidades médias: o caso de Santa Cruz do SulRS. 2012. 189 p. Dissertação (Programa de Pós-Graduação em Desenvolvimento Regional Mestrado e Doutorado) -Universidade de Santa Cruz do Sul, Santa Cruz do Sul, 2012.

- Reestruturação Urbana e Mudanças na Dinâmica e Organização da Área Central de Santa Cruz do Sul - RS. 2017. 322 f. Dissertação (Programa de Pós-Graduação em Desenvolvimento Regional - Mestrado e Doutorado) - Universidade de Santa Cruz do Sul, Santa Cruz do Sul, 2017.

PREFEITURA DE SANTA CRUZ DO SUL. Desenvolvido por DROP. Apresenta informações gerais do município. Disponível em: <http://www.santacruz.rs.gov.br/municipio/historico-do-municipio>. Acesso em: 10 mar. 2018

ROSSATTO, D. R.; TSUBOY, M. S. F.; FREI, F. Arborização urbana na cidade de Assis-SP: uma abordagem quantitativa. Revista da Sociedade Brasileira de Arborização Urbana, v.3, n.3, p.116, 2008.

SANTA CRUZ DO SUL. Lei n. 1.664, de 29 de dezembro de 1977. Santa Cruz do Sul [s.n.], 1977. . Lei Ordinária n. 2473, de 12 de maio de 1993. Santa Cruz do Sul [s.n.], 1993. . Lei Complementar n. 06, de 26 de fevereiro de 1998. Santa Cruz do Sul: [s.n.], 1998. . Lei n. 122/E/2001 - Estabelece normas de manejo, proteção e conservação da arborização no Município de Santa Cruz do Sul e dá outras providências. Santa Cruz do Sul: [s.n.], 2001.

. Lei Complementar n. 335, de 03 de janeiro de 2007. Santa Cruz do Sul: [s.n.], 2007. . Projeto de Lei n. 100/E, de 30 de setembro de 2011. Santa Cruz do Sul [s.n.], 2011. . Lei Ordinária n. 6.447, de 4 de janeiro de 2012. Santa Cruz do Sul [s.n.], 2012. . Lei Ordinária n. 7284, de 20 de maio de 2015. Santa Cruz do Sul [s.n.], 2015. . Projeto de Lei complementar, de 2018. Santa Cruz do Sul [s.n.], 2018. 
SILVEIRA, R. L. L. da. Cidade, corporação e periferia urbana: acumulação de capital e segregação espacial na (re)produção do espaço urbano. Santa Cruz do Sul: EDUNISC, 2003.

. Dinâmica do mercado imobiliário e práticas espaciais no processo de urbanização da capital mundial do tabaco. In: SILVEIRA, Rogério L. L. Dinâmica Imobiliária e Reestruturação Urbana na América Latina. Santa Cruz do Sul: EDUNISC, 2006. p. 193-237.

TORTORELLI, L. A. Maderas y bosques argentinos. Buenos Aires: Acme, 1956. 580 p.

WINK, R. Santa Cruz do Sul e sua evolução urbana - 1855 a 2000. Dissertação (Programa de Pós-graduação em Desenvolvimento Regional). UNISC: Santa Cruz do Sul. 2000.

. Santa Cruz do Sul: urbanização e desenvolvimento. Santa Cruz do Sul: Edunisc, 2002.

YANG, J. et al. The urban forest in Beijing and its role in air pollution reduction. Urban Forestry and Urban Greening, v.3, p.65-78, 2005. 